\title{
3 Pesearchs Surure \\ Economic Evaluation of Remote Patient Monitoring System in Patients With Type 2 Diabetes
}

\section{Sahar Salehi}

Tehran University of Medical Sciences

Alireza Olyaeemanesh ( $\nabla$ arolyaee@gmail.com )

Associate Professor, National Institute for Health Research and Health Equity Research Center, Tehran

University of Medical Science, Tehran, Iran

\section{Mohammad Reza Mobinizadeh}

Tehran University of Medical Sciences

\section{Ensieh Nasli Esfahani}

Shariati Hospital

\section{Hossein Riazi}

Endocrinology and Metabolism Research Institute

\section{Alireza Mahdavi Hezaveh}

Ministry of Health and Medical Education

Mahdi Azadbakht

Lorestan University

\section{Elahe Bavand pour}

Kermanshah University of Medical Sciences

\section{Maryam Jamali}

Tehran University of Medical Sciences

\section{Research Article}

Keywords: Remote Monitoring, Glycosylated Hemoglobin, Type 2 Diabetes, Economic Evaluation

Posted Date: January 11th, 2021

DOI: https://doi.org/10.21203/rs.3.rs-132385/v1

License: (c) (1) This work is licensed under a Creative Commons Attribution 4.0 International License. Read Full License 


\section{Abstract}

Introduction: Nowadays, an alternative model for evolution of health care is required to reduce the chronic illness burden notably diabetes; to this end, using the remote patient monitoring system is recommended. This system virtually eliminates distance barriers and constantly monitors the patients' information on urban and rural areas. Moreover, in case of trouble, patients are immediately supported and quick warnings are sent to the health care provider and the patient, if necessary. This study aimed to investigate the economic evaluation of the remote type 2 diabetes monitoring for controlling the blood glucose (glycosylated hemoglobin) compared to routine type 2 diabetes care.

Methods: Economic evaluation was carried out using the finished cost of the remote type 2 diabetes monitoring technology and the routine treatment, incremental cost-effectiveness ratio as well as one-way and multiple sensitivity analysis using the key variables such as population, cost items, the minimum, maximum and average population size. In this study, the remote type 2 diabetes monitoring technology was compared with the routine treatment.

Results: The results showed that, considering the incremental cost-effectiveness ratio in the base model, the remote type 2 diabetes monitoring system in comparison with routine treatment of type 2 diabetes was placed in the second quarter (more effective and affordable technology) of the graph as the most dominant alternative. The results of the two-way sensitivity analysis revealed that the research findings are consistent in terms of cost and population variables and in all cases were included in the second quarter (more effective and affordable technology) in the incremental cost-effectiveness ratio graph and were dominant compared to the routine treatment.

Conclusion: Remote patient monitoring is a dominant alternative compared to routine treatment. Further evidence on long-term remote patient monitoring experience is needed for future studies. Results indicated that remote type 2 diabetes monitoring interventions play an effective role in reducing $\mathrm{HbA} 1 \mathrm{c}$ that may be considered the rationale for policy makers on domestication of this technology.

\section{Introduction}

Diabetes is a chronic disease that imposes huge expenditure on health care systems [1]. Diabetes is now the fourth leading cause of physician visits in Western communities and the seventh leading cause of death across the United States [2, 3]. Regarding the remarkable incidence over the past two decades, the number of diabetes is expected to reach up to 438 million by 2030 [4]. In Iran, 9.3\% of people are infected by diabetes, which by $2030,13.1 \%$ of Iranians will suffer from this condition [5]. Diabetes complications include neuropathy, retinopathy, cardiovascular and cerebrovascular disease. It is time-consuming and costly to treat diabetes with relatively low success. In terms of age and gender, the costs of diabetic patients are estimated 20.3-fold higher than the costs of other patients $[3,6]$.

It is difficult to access specialists and proper assistance in service offering units in villages and remote areas. Factors like physical disability, geographical, financial, and time limitations prevent people in these areas to visit specialized centers in the city at the right time. It creates injustice and imposes costs on the health 
system [7]. Remote patient monitoring (RPM) lessens such limitations by gathering data on patient health from places such as homes using digital technologies and then transmitting data to health care providers in various locations via telecommunication lines for more consideration and receiving feedback. RPM involves the analysis of physiological parameters (e.g., blood sugar, blood pressure, and weight), counseling, education, and early diagnosis $[8,9]$.

Information of patients is monitored by the service providers in constant manner. In case of any problem, patients are supported immediately by alarming service providers and someone who accompanies the patient if necessary, and thus, patients and their families no longer should be worried about the problem [10].

RPM technology reduces the number of hospitalizations, visits to the emergency department, and the length of hospitalizations, according to evidence. RPM is thereby an efficient solution for disease prevention, proper access to services, diminishing health care costs, and lessening complications. With RPM, resources are used more efficiently [10-13] and the patient's quality of life is increased remarkably [13].

These services are provided accurately and strict regulations are followed to maintain confidentiality over patients' information [9]. Hence, RPM can be more affordable than other approaches [14].

The management of chronic conditions depends on the patient's participation and ability to follow the physician's recommendations in the long run. Patient education is critical for disease management [15]. The time saved by implementing RPM technology improves efficiency and allows healthcare providers to allocate more time to educate the patient from a distance and communicate with him or her [16].

Owing to proper interaction between the care system and the patient, RPM promotes the efficiency of diabetes therapy and enhances physicians' ability to monitor and manage patients in the health system. For example, in patients with type 2 diabetes, a $1 \%$ reduction in the $\mathrm{HbA} 1 \mathrm{c}$ level results in a $16 \%$ reduction in heart failure, a $19 \%$ lower risk of developing cataracts, a $43 \%$ lower risk of amputation or death from peripheral vascular disease, and in general, a $25 \%$ reduction in complications such as retinopathy, neuropathy, and diabetic nephropathy $[17,18]$.

RPM has resulted in sustainable growth in markets in many countries, including the USA, Canada, Mexico, Germany, France, the United Kingdom, Italy, Spain, Russia, Japan, China, India, Australia, South Korea, Taiwan, Brazil, Turkey, Venezuela, Saudi Arabia, and South Africa [19].

In 2016, 7.1 million people attended digital health programs. As estimated by researchers, the number of patients receiving RPM medical care will reach 50.2 million over the next four years by fixing restrictions with RPM, including lack of awareness, the resistance of health care professionals to accept RPM, the lack of appropriate refund policies, and the challenges in the RPM equipment market. Out of this, 25.2 million patients will use RPM technology, and in turn, the application of RPM technology will reach $38 \%$ from 2016 to 2022 [20-23].

Hence, this study deals with the economic evaluation of remote patient monitoring (RPM) system in patients with type 2 diabetes in Iran's primary care system in order to provide physicians with the sufficient trustworthy evidence so as to encourage them to use this effective technology. It also aims to convince the health system 
and insurance policy-makers to promote and allocate the funds, reimburse for services and reduce the heavy burden that diabetes imposes on the health system and families.

\section{Methods}

The economic aspects are addressed through the relationship between costs and outcomes. In the present study, outcomes, the decrease in hemoglobin A1c (HbA1c) levels and cost were prospectively calculated through standard costing (Iran does not currently this technology).

Costing of the routine treatment was calculated focusing on the level of health care house. Finally, Incremental cost-effectiveness ratio (ICER) and one-way and multiple sensitivity analysis were carried out using the variables such as population, cost items, minimum, maximum and average population size and by using the consequential aggregated results obtained from the meta-analysis of Salehi et al. [2].

It is noteworthy that in literature review, there was no a similar economic evaluation model, including the decision tree and Markov so that it could be used for domestication. Moreover, a simple ICER had been employed for economic evaluation in most studies.

\section{A) Costing}

Due to the fact that T2D remote monitoring technology is not available in Iran and therefore, there was no study on the relevant outcomes, the results of the systematic review and meta-analysis of Salehi et al. [2] were used to extract outcomes and the probability of their occurrence; then, the costs of the equipment as well as the outcomes were calculated based on the Iranian currency (Rials) by the diabetes program experts and information technology specialists of the Ministry of Health.

The costs were converted into Iranian's currency based on the dollar foreign exchange reference rate of the Central Bank in 2018 (42000 Rials per dollar). The perspective of the Iran's Ministry of Health as the service provider was selected for economic evaluation. Cost-effectiveness analysis (CEA) was used for data analysis by considering the reduction of $\mathrm{HbA} 1 \mathrm{c}$ outcome and sensitivity analysis.

\section{B) Calculation of the unit cost of T2D remote monitoring technology remote monitoring technologies (basic model)}

The costs were divided into five categories of capital (the cost of equipment and devices), building purchase, staff, overhead costs and consumables and others in order to carry out the calculations.

All construction, equipment and personnel costs were calculated in their final cost to their working hours throughout the year. The cost of physical space was calculated taking into account the minimum area required for the health house $(100 \mathrm{~m})$ in routine treatment and six meters for remote patient monitoring and the approximate price of the property was determined as 150,000,000 according to the enactment of the network management department of the Ministry of Health. The use period of the building was 30 years and the depreciation coefficient was considered 1.7. 
According to the price inquired from the network management department of the Ministry of Health and the director of Diabetes Program of the Ministry of Health, the cost of the equipment required for each method was calculated based on the actual amount paid in 2018. The service life of the equipment was considered five years and the depreciation coefficient was determined 2.5.

In addition, the cost of human force for routine treatment was estimated based on two male and female health workers during office hours and working hours that the physician of the health care center, along with in-service training, spends once a week (1-3 hours) in the health house. The cost of human force for T2D remote monitoring technology remote monitoring technology was estimated by examining two 24-hour shift health workers and consultation fee of the remote general physician (if needed). Since there is no enactment on the number of staff and remote patient monitoring equipment, the cost items of this technology were estimated according to the IT specialists' views of the Ministry of Health. Besides, as the introduction of the intervention leads to a change in the allocation of time for the service provider by the staff, it affects the costs of the staff. Given that staff do not work full time in the routine treatment of patients, they should be motivated to provide full time services by increasing the payment. Consequently, incremental costs for motivating the staff in order to provide 24 - hour services are included in the analysis.

The price announced by the product support companies and the director of the Diabetes Program of the Ministry of Health was taken into account for calculation of the finished cost of the consumables including office supplies and stationery, network and computer systems maintenance, and the like. Furthermore, according to the director of the Diabetes Program of the Ministry of Health, the number of tests that can be conducted over the course of one year (300 working days) was estimated up to four times a year.

\section{C) Cost-effectiveness analysis using an incremental cost- effectiveness plane}

Cost-effectiveness plane or graph is one of the useful means for displaying the decision-making rules.

The vertical axis of the graph indicates the difference between the unit price of T2D remote monitoring technology and their routine treatment and the horizontal axis shows the difference between the outcomes of this technology and routine treatment. The lines divide the all possible combinations of effect and cost into four circle quarters. In the northwest quarter, the costs are higher and the effects are lower, thus, the intervention is undesirable in all its dimensions and is in the worst condition that should be overridden by its alternatives and this intervention should not be used for efficiency reasons. In the southeast quarter, costs are lower and effects are higher, so intervention overrides alternatives and should be used for efficiency reasons. In the other two quarters, higher effectiveness is achieved at a higher cost, such as the northeast quarter or is obtained by reducing the costs and impact, such as the southwest quarter. Using the intervention for efficiency reasons in these two quarters depends on the trade-off and the exchange between costs and effects [3]. This ratio is calculated as follows:

$$
I C E R=\frac{\left(C_{1}-C_{0}\right)}{\left(E_{1}-E_{0}\right)}
$$


Where ICER denotes the incremental cost-effectiveness ratio, $\mathrm{C} 1$ denotes the finished cost of the intervention group and $\mathrm{C} 0$ denotes the finished cost of the control group, E1 denotes the outcome of the intervention group and EO denotes the outcome of the control group.

\section{C-1) Outcomes}

$\mathrm{HbA1c}$ is the desired outcome of the present study. According to the meta-analysis of Salehi et al. [2], at the end of the study, the mean $\mathrm{HbA} 1 \mathrm{c}$ in the control group was and in the intervention group was $8.005(\mathrm{SD}=$ $0.57 \mathrm{SD})$ and $7.517(\mathrm{SD}=0.47)$, respectively.

\section{C-2) Calculations}

The collected costs data were entered into Excel worksheets and the finished cost of technology was calculated and analyzed using the formula for calculating the variable decline balance.

\section{Results}

\section{A) The annual cost of the systems}

According to the research estimations, the estimated annual cost for routine treatment is 2219817029 Rials (Table 1) and for the T2D remote monitoring technology remote monitoring system is 744710000 Rials (Table 2).

Table 1

costs details of routine treatment

\begin{tabular}{|lllll|}
\hline Cost list & $\begin{array}{l}\text { Cost of purchasing items } \\
\text { (Rials) }\end{array}$ & Year & $\begin{array}{l}\text { Depreciation } \\
\text { rate }\end{array}$ & $\begin{array}{l}\text { Cost/year } \\
\text { (Rials) }\end{array}$ \\
\hline $\begin{array}{l}\text { Cost of equipment and } \\
\text { devices }\end{array}$ & 358300000 & 5 & 1.7 & 60911000 \\
\hline Building cost & 150000000 & 30 & 2.7 & 13500000 \\
\hline Cost of consumables & - & - & - & 497340000 \\
\hline Cost of human force & - & - & - & 1213262021 \\
\hline Other costs & - & - & - & 415008 \\
\hline
\end{tabular}


Table 2

cost details of T2D remote monitoring

\begin{tabular}{|lllll|}
\hline Cost list & $\begin{array}{l}\text { Cost of purchasing items } \\
\text { (Rials) }\end{array}$ & Year & $\begin{array}{l}\text { Depreciation } \\
\text { rate }\end{array}$ & $\begin{array}{l}\text { Cost/year } \\
\text { (Rials) }\end{array}$ \\
\hline $\begin{array}{l}\text { Cost of equipment and } \\
\text { devices }\end{array}$ & 70000000 & 5 & 1.7 & 11900000 \\
\hline Building cost & 90000000 & 30 & 2.7 & 15471000 \\
\hline Cost of consumables & - & - & - & 117630000 \\
\hline Cost of human force & - & - & - & 24000000 \\
\hline Other costs & - & - & - & 0 \\
\hline
\end{tabular}

\section{B) Incremental cost-effectiveness results}

According to the calculations and according to Tables 1 and 2, T2D remote monitoring technology, the rate of incremental cost-effectiveness ratio compared to routine treatment of T2D patients were considered in the second quarter (more effective and affordable technology) and this system will be the dominant alternative.

\section{C) Sensitivity analysis}

For uncertain parameters, a two-way sensitivity analysis with recalculation of results after 5,10 and $15 \%$ change in cost parameter values and considering the minimum $(n=500)$, maximum $(n=1500)$ and average $(n=1300)$ population was carried out under the auspices of the health houses (Table 3$)$. These changes have been brought about based on an inquiry from the Ministry of Health. 
Table 3

ICER two-way sensitivity analysis of T2D remote monitoring technology compared to the routine treatment

\begin{tabular}{|c|c|c|c|c|}
\hline \multirow{2}{*}{$\begin{array}{l}\text { Parameter } \\
\text { Base }\end{array}$} & & \multicolumn{2}{|c|}{$\begin{array}{l}\text { Finished Cost (Rials) of treatment for each } \\
\text { T2D patient }\end{array}$} & \multirow[t]{2}{*}{$\begin{array}{l}\text { ICER (COST/OUT } \\
\text { COME) }\end{array}$} \\
\hline & & RPM technology & Routine treatment & \\
\hline \multirow[t]{6}{*}{ Cost } & $+0.5 \%$ & 6014965 & 17929291 & -24451028.48 \\
\hline & $+10 \%$ & 6301392 & 18783067 & -25625363.46 \\
\hline & $+15 \%$ & 6587819 & 19636843 & -2677969.44 \\
\hline & $-0.5 \%$ & 5442111 & 16221740 & -22122360.57 \\
\hline & $-10 \%$ & 5155685 & 15367964 & -20958023.53 \\
\hline & $-15 \%$ & 4869258 & 14514188 & -19793688.55 \\
\hline \multirow[t]{3}{*}{ Population } & $\begin{array}{l}\text { Minimum } \\
\text { population }\end{array}$ & 14894200 & 44396341 & -605454.73 \\
\hline & $\begin{array}{l}\text { Average } \\
\text { population }\end{array}$ & 5728538 & 17075516 & -23286695.55 \\
\hline & $\begin{array}{l}\text { Maximum } \\
\text { population }\end{array}$ & 4964733 & 14798780 & -20181801.58 \\
\hline
\end{tabular}

According to different scenarios to evaluate the effectiveness with different domains by considering the research variables such as population, cost items, minimum, maximum and average population size and increase and decrease of $5 \%, 10 \%, 15 \%$ of costs based on an inquiry from the diabetes department of the Ministry of Health (Table 3), the results revealed that it was a decreasing variable, and since the decrease in the index is indicative of improvement of the patient outcomes and the decrease in $\mathrm{HbA} 1 \mathrm{c}$ is inherently a positive index, the absolute value of the denominator of the ICER formula was considered.

\section{C-1: A 5\% increase in control and intervention group costs}

By $5 \%$ increase in the costs of the control and intervention group, the ICER value was approximately equal to -24451028 , showing an increase of 24451028 Rials in costs per unit of HbA1c reduction. This demonstrates that remote patient monitoring technology is not sensitive to the $5 \%$ price increase and is still a dominant alternative for routine treatment (it was considered in the second quarter, namely more effective and affordable).

\section{C-2: A $10 \%$ increase in the costs of the control and intervention group}

By $10 \%$ increase in the costs of the control and intervention group, the ICER value was approximately equal to -25615363 , showing an increase of 25615363 Rials in costs per unit of HbA1c reduction. This demonstrates that remote patient monitoring technology is not sensitive to the $10 \%$ price increase and is still a dominant alternative for routine treatment (it was considered in the second quarter, namely more effective and affordable). 


\section{C-3: A 15\% increase in the costs of the control and intervention group}

By $15 \%$ increase in the costs of the control and intervention group, the ICER value was approximately equal to -26779698, showing an increase of 26779698 Rials in costs per unit of HbA1c reduction. This demonstrates that remote patient monitoring technology is not sensitive to the $15 \%$ price increase and is still a dominant alternative for routine treatment (it was considered in the second quarter, namely more effective and affordable).

\section{C-4: A $5 \%$ reduction in the costs of the control and intervention group}

By $5 \%$ reduction in the costs of the control and intervention group, the ICER value was approximately equal to -22122360 , showing a reduction of 2212236 Rials in costs per unit of HbA1c reduction. This demonstrates that remote patient monitoring technology is not sensitive to the $5 \%$ price reduction and is still a dominant alternative for routine treatment (it was considered in the second quarter, namely more effective and affordable).

\section{C-5: A $10 \%$ reduction in the costs of the control and intervention group}

By $10 \%$ reduction in the costs of the control and intervention group, the ICER value was approximately equal to -20958023 , showing a reduction of 20958023 Rials in costs per unit of HbA1c reduction. This demonstrates that remote patient monitoring technology is not sensitive to the $10 \%$ price reduction and is still a dominant alternative for routine treatment (it was considered in the second quarter, namely more effective and affordable).

\section{C-6: A 15\% reduction in the costs of the control and intervention group}

By $15 \%$ reduction in the costs of the control and intervention group, the ICER value was approximately equal to -19793688 , showing a reduction of 19793688 Rials in costs per unit of HbA1c reduction. This demonstrates that remote patient monitoring technology is not sensitive to the $15 \%$ price reduction and is still a dominant alternative for routine treatment (it was considered in the second quarter, namely more effective and affordable).

C-7: The minimum frequency of the population under the auspices of health houses $(n=500)$

In the case of the minimum frequency of the population under the auspices of health houses $(n=500)$, the ICER value is approximately equal to -60545404 , indicating 605454044 Rials cost per unit of HbA1c reduction. This demonstrates that remote patient monitoring technology is not sensitive to the minimum population size and is still a dominant alternative for routine treatment (it was considered in the second quarter, namely more effective and affordable). 


\section{C-8: The average frequency of the population under the auspices of health houses $(n=1300)$}

In the case of the average frequency of the population under the auspices of health houses $(n=500)$, the ICER value is approximately equal to -23286695 , indicating 23286695 Rials cost per unit of HbA1c reduction. This demonstrates that remote patient monitoring technology is not sensitive to the average population size and is still a dominant alternative for routine treatment (it was considered in the second quarter, namely more effective and affordable).

\section{C-9: The maximum frequency of the population under the auspices of health houses $(n=1500)$}

In the case of the maximum frequency of the population under the auspices of health houses $(n=1500)$, the ICER value is approximately equal to -20181801, indicating 20181801 Rials cost per unit of HbA1c reduction. This demonstrates that remote patient monitoring technology is not sensitive to the maximum population size and is still a dominant alternative for routine treatment (it was considered in the second quarter, namely more effective and affordable).

The results of two-way sensitivity analysis showed that the findings of the study in different conditions are a dominant alternative over routine treatment. The results of two-way sensitivity analysis revealed that the findings of the study are consistent to cost and population parameters [1] and in all cases were considered in the second quarter (more efficient and affordable technology).

\section{Discussion}

The results of the economic evaluation showed that T2D remote monitoring technology is more effective and affordable (second quarter) compared to the routine treatment of T2D patients and is the dominant alternative. Moreover, the results of the two-way sensitivity analysis showed that the findings of the study are consistent in terms of cost and population size variables and in all cases are in the second quarter (more effective and affordable technology).

The most paramount advantage of remote patient monitoring is to help people who are unable to refer the clinics due to geographical constraints, infectious diseases such as Covid-19, or resource scarcity. Of Course, after the prevalence of the infectious coronavirus pandemic, this Technology is required more than ever before. By calculating ICER, it is concluded that the T2D remote monitoring technology is more cost-effective compared to routine treatment of patients with diabetes because they were considered in the second quarter (more effective and affordable technology) of the ICER graph and consequently, this technology is the dominant alternative. This result was consistent with that of other studies. A 2017 randomized clinical trial study by Warren et al. revealed that total health care costs in the remote patient monitoring group, including intervention costs, were lower than those of conventional care (average $\$ 3,781$ vs. $\$ 4662 ; \mathrm{P}<0.001$ ). Clinically and statistically, remote medical benefits were achieved at a lower cost. Therefore, the use of remote medical intervention was cost-effective with more health benefits than conventional care [4].

Fountoulakis et al. indicated that the intervention was more cost-effective for patients who lived more than $100 \mathrm{~km}$ from the health house. The results revealed that remote patient monitoring technology is more costeffective than routine treatment [4-6]. 
This technology imposes lower costs on the health care system and is more effective than routine treatment and no side-effects have been reported so far [2]. Besides, high accuracy and confidentiality of information are included. In addition, results obtained from the patient-measured $\mathrm{HbA} 1 \mathrm{c}$ are generally similar to those of the patient's professional tests [7]. Remote patient monitoring technology that is more cost-effective and affordable, provides better monitoring and higher satisfaction for patients [15]. Implementations of this technology is justifiable compared to the conventional treatment methods that imposes the variable costs.

The annual cost of routine treatment is 2.98 times the annual cost of remote monitoring technology for T2D. As a result, it is cost-effective.

\section{Limitations}

There was no similar economic model including decision tree and Markov to be used for calculating the QALY and conduct the economic evaluation based on QALY or an economic evaluation that would help convert $\mathrm{HbA1c}$ reduction to QALY. Therefore, the domestication was not possible.

\section{Conclusion}

The results indicate that T2D remote monitoring technology is more effective and cost-effective in reducing $\mathrm{HbA} 1 \mathrm{c}$ compared to routine care and can be used as a rationale for policy-makers to domesticate this technology. Evidence on the long-term remote patient monitoring experience is required for future studies. Considering that there is no T2D remote monitoring technology in Iran and investment in information technology will increase in future, further studies are needed on this field and the infrastructure for the deployment of this technology should be developed to provide widespread use of this very useful, effective and affordable technology in Iran.

\section{Declarations}

Ethics approval and consent to participate not applicable

Consent for publication not applicable

Availability of data and materials All data used and analysis performed are available from corresponding author on reasonable request.

Competing interests The authors declare that they have no competing interests.

Funding This study not-for-profit sector and did not receive any specific grant.

Authors' contributions $A O$ and MM Designed the study. SS, MA, EB and MJ collected the data, MM and SS performed statistical analysis and drafted the manuscript. ENE and HR Assisted in design of study.AO, MM and $\mathrm{AMH}$ Commented and help for interpretation of data. All authors read and approved the final manuscript.

Acknowledgements The authors would like to thank all experts who participate in this research. Without them, our work would have been harder. 


\section{References}

1. Logan AG, Mclsaac WJ, Tisler A, Irvine MJ, Saunders A, Dunai A, et al. Mobile phone-based remote patient monitoring system for management of hypertension in diabetic patients. American journal of hypertension. 2007;20(9):942-8.

2. Organization WH. Global report on diabetes: World Health Organization; 2016.

3. Control CfD, Prevention. National diabetes statistics report, 2017. Atlanta, GA: Centers for Disease Control and Prevention, US Dept of Health and Human Services. 2017.

4. Fathi ahmadsaraei N, Neshat doost Ht, Manshaee Gr, Nadi Ma. The Effectiveness of Acceptance and Commitment Therapy on Quality of Life among Patients with Type 2 Diabetes. Iranian Journal of Health Education and Health Promotion. 2016;4(1):31-9.

5. Whiting DR, Guariguata L, Weil C, Shaw J. IDF diabetes atlas: global estimates of the prevalence of diabetes for 2011 and 2030. Diabetes research and clinical practice. 2011;94(3):311-21.

6. Organization WH. Use of glycated haemoglobin $(\mathrm{HbA1c})$ in diagnosis of diabetes mellitus: abbreviated report of a WHO consultation. 2011.

7. Holl F, Munteh P, Burk R, Swoboda W. Improving Access to Care in Rural Africa Through the Use of Telemedicine: Using a mHealth System as a Case Study. Studies in health technology and informatics. 2017;244:105-

8. Vegesna A, Tran M, Angelaccio M, Arcona S. Remote patient monitoring via non-invasive digital technologies: a systematic review. Telemedicine and e-Health. 2017;23(1):3-17.

9. Chase HP, Pearson JA, Wightman C, Roberts MD, Oderberg AD, Garg SK. Modem transmission of glucose values reduces the costs and need for clinic visits. Diabetes care. 2003;26(5):1475-9.

10. Bonsignore L, Bloom N, Steinhauser K, Nichols R, Allen T, Twaddle M, et al. Evaluating the Feasibility and Acceptability of a Telehealth Program in a Rural Palliative Care Population: TapCloud for Palliative Care. Journal of pain and symptom management. 2018.

11. Yoo B-K, Kim M, Sasaki T, Hoch JS, Marcin JP. Selected use of telemedicine in intensive care units based on severity of illness improves cost-effectiveness. Telemedicine and e-Health. 2018;24(1):21-36.

12. Smith NM, Satyshur RD. Pediatric diabetes telemedicine program improves access to care for rural families: role of APRNs. Pediatric Nursing. 2016;42(6):294.

13. Noah B, Keller MS, Mosadeghi S, Stein L, Johl S, Delshad S, et al. Impact of remote patient monitoring on clinical outcomes: an updated meta-analysis of randomized controlled trials. NPJ Digital Medicine. 2018;1(1):2.

14. Wilson LS, Maeder AJ. Recent directions in telemedicine: review of trends in research and practice. Healthcare informatics research. 2015;21(4):213-22.

15. Bayliss EA, Steiner JF, Fernald DH, Crane LA, Main DS. Descriptions of barriers to self-care by persons with comorbid chronic diseases. The Annals of Family Medicine. 2003;1(1):15-21.

16. Coye MJ, Haselkorn A, DeMello S. Remote patient management: technology-enabled innovation and evolving business models for chronic disease care. Health Affairs. 2009;28(1):126-35. 
17. community Tgd. Blood Glucose Care 2018 [cited 2018 April]. Available from: https://www.diabetes.co.uk/what-is-hba1c.html.

18. Riazi H, Larijani B, Langarizadeh M, Shahmoradi L. Managing diabetes mellitus using information technology: a systematic review. Journal of Diabetes \& Metabolic Disorders. 2015;14(1):49.

19. Onkar Sumant PJ. Remote Patient Monitoring Market by Condition (Congestive Heart Failure, Diabetes, Chronic Obstructive Pulmonary Disease, Blood Pressure, and Mental Health), Components (Devices and Software) - Global Opportunity Analysis and Industry Forecast, 2014 - 20222016 Sep.

20. Global Remote Patient Monitoring Systems Market. 2017.

21. Baum P, Abadie F, Lupiañez FV, Maghiros I, Mora EV, Talaya MBZ. Market Developments-Remote Patient Monitoring and Treatment, Telecare, Fitness/Wellness and mHealth. Strategic Intelligence Monitor on Personal Health Systems, Phase. 2013;2.

22. Hossain MS, editor Patient status monitoring for smart home healthcare. Multimedia \& Expo Workshops (ICMEW), 2016 IEEE International Conference on; 2016: IEEE.

23. Mack H. Remote patient monitoring market grew by 44 percent in 2016, report says 2017 [Available from: http://www.mobihealthnews.com/content/remote-patient-monitoring-market-grew-44-percent-2016report-says.

24. Salehi S, Olyaeemanesh A, Mobinizadeh M, Nasli-Esfahani E, Riazi H. Assessment of remote patient monitoring (RPM) systems for patients with type 2 diabetes: a systematic review and meta-analysis. Journal of Diabetes \& Metabolic Disorders. 2020:1-13.

25. Farbod EA, R A. Health Care Economics. edition s ed. ran- Tehran2014.

26. Fountoulakis S, Papanastasiou L, Gryparis A, Markou A, Piaditis G. Impact and duration effect of telemonitoring on $\mathrm{HbA} 1 \mathrm{c}, \mathrm{BMI}$ and cost in insulin-treated Diabetes Mellitus patients with inadequate glycemic control: A randomized controlled study. Hormones. 2015;14(4):632-43.

27. Shea S, Weinstock RS, Starren J, Teresi J, Palmas W, Field L, et al. A randomized trial comparing telemedicine case management with usual care in older, ethnically diverse, medically underserved patients with diabetes mellitus. Journal of the American Medical Informatics Association. 2006;13(1):4051.

28. Warren R, Carlisle K, Mihala G, Scuffham PA. Effects of telemonitoring on glycaemic control and healthcare costs in type 2 diabetes: a randomised controlled trial. Journal of telemedicine and telecare. 2018;24(9):586-95.

29. Type of telemedicine and its benefits for patients and physicians 2018 [Available from: https://pafcoerp.com/-\%D8\%B3\%DB\%8C\%D8\%B3\%D8\%AA\%D9\%85-

\%D9\%85\%D8\%AF\%DB\%8C\%D8\%B1\%DB\%8C\%D8\%AA-

\%D8\%A2\%D9\%85\%D9\%88\%D8\%B2\%D8\%B4-/articleid/429/\%D8\%A7\%D9\%86\%D9\%88\%D8\%A7\%D8\%B9\%D9\%BE\%D8\%B2\%D8\%B4\%DA\%A9\%DB\%8C-\%D8\%A7\%D8\%B2-\%D8\%B1\%D8\%A7\%D9\%87$\% \mathrm{D} 8 \% \mathrm{AF} \% \mathrm{D} 9 \% 88 \% \mathrm{D} 8 \% \mathrm{~B} 1$. 